\title{
3-Isoxazolidinone: A New Achiral Template for Enantioselective Transformations ${ }^{\dagger}$
}

\author{
Mukund P. Sibi, ${ }^{*}$ Brandon Gustafson, and Julien Coulomb \\ Department of Chemistry and Molecular Biology, North Dakota State University, Fargo, ND 58108 \\ ${ }^{*}$ E-mail: Mukund.Sibi@ndsu.edu \\ Received September 22, 2009, Accepted November 6, 2009
}

Key Words: Achiral template, 3-Isoxazolidinone, Diels-Alder, Rotamer control, Chiral Lewis acid

Achiral templates play an important role in a variety of asymmetric transformations. ${ }^{1}$ Achiral templates allow for the easy introduction of the desired substrate, removal from the product, contain donor atoms for interaction with Lewis acids, and most significantly possess rotamer control elements such that reactions can occur predominantly from a single conformer. ${ }^{2}$ The issue of rotamer control is illustrated using an $\alpha$ methylacrylate as a substrate (Figure 1). In the case of the traditional oxazolidinone template, there are $\mathrm{A}^{1,3}$ interactions in the $s$-cis rotamer $\mathbf{1}$ and the $s$-trans rotamer $\mathbf{2}$ leading to a less reactive and/or selective starting material in asymmetric transformations. ${ }^{3}$ We hypothesized that the isomeric 3 -isoxazolidinone template possessing a less bulky oxygen atom in place of the $\mathrm{C}-4$ methylene group would alleviate the $\mathrm{A}^{1,3}$ interactions and lead to a more reactive and/or selective transformations from either the $s$-cis 3 or the $s$-trans rotamer 4 . $^{4}$ A proof of principle study to evaluate the effectiveness of 3-isoxazolidinone as a template is described here using enantioselective DielsAlder reactions. ${ }^{5}$

The new achiral template, 3-isoxazolidinone, is readily synthesized in good yield in two steps from commercially available materials. ${ }^{6}$ Our initial experiments involved Diels-Alder reaction of the template derived from acrylate and crotonate with cyclopentadiene in an effort to gauge its reactivity (eqn 1). For these reactions we employed chiral catalysts prepared from different Lewis acids and bisoxazoline ligands $\mathbf{9}^{7}$ and $\mathbf{1 0}{ }^{8}$ Results from these experiments are shown in Table 1. Cycloaddition with acrylate $\mathbf{5}$ using copper triflate and ligand $\mathbf{9}$ gave the cycloadduct as a single endo isomer in high yield and very high selectivity (entry 1). Magnesium triflimide/9 combination was less effective with respect to enantioselectivity for the major endo adduct (entry 2). A combination of nickel perchlorate and $\mathbf{1 0}$ also gave the endo adduct in high yield and selectivity (entry 3). Cycloadditions with crotonate 6 were evaluated next (entries 4-6). In contrast to reaction with the more reactive acrylate $\mathbf{5}$, reaction with crotonate $\mathbf{6}$ was less efficient with respect to both yield and selectivity and also required elevated temperature.

Reaction with copper triflate/9 gave the major endo adduct in good yield and selectivity (entry 4). Reaction using magnesium triflimide/ $\mathbf{9}$ as a catalyst was not very effective with respect to selectivity (entry 5). Nickel perchlorate/10 also gave the major endo adduct in good yield and selectivity (entry 6).

${ }^{\dagger}$ This paper is dedicated to Professor Sunggak Kim on the occasion of his honorable retirement.
Cycloadditions with the $\alpha$-methylacrylate 3 were investigated next in an effort to evaluate if rotamer control installed in the template plays a role in the efficiency of the reaction (eqn 2$).{ }^{9}$ These results are shown in Table 2. Cycloaddition using magnesium triflimide/9 gave the cycloadduct as a nearly 1:1 mixture in low yield with no selectivity (entry 1). Zinc triflimide as a Lewis acid was also ineffective (entry 2 ). Iron triflimide/9 gave the endo/exo adducts in high yield and modest selectivity (entry 3). Reaction with copper triflate/9 was less effective and gave the adducts in modest selectivity (entry 4). Interestingly, the products were enantiomeric to that obtained with iron and zinc Lewis acids. Cooling the reaction temperature to 0 or $-20{ }^{\circ} \mathrm{C}$ led to substantial improvement in selectivity (entries 5 and 6). However, the chemical yields were very low. Doubling the catalyst loading to $30 \mathrm{~mol} \%$ led to improvement in chemical

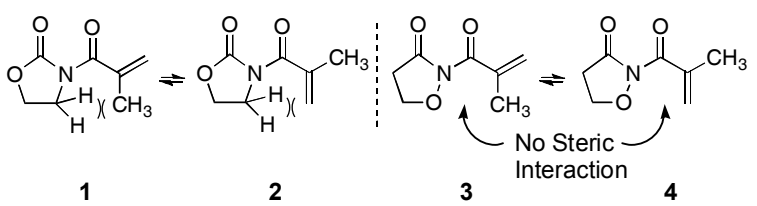

Figure 1. Rotamer control with different templates.

Table 1. Cycloadditions with acrylate 5 and crotonate $\mathbf{6}$

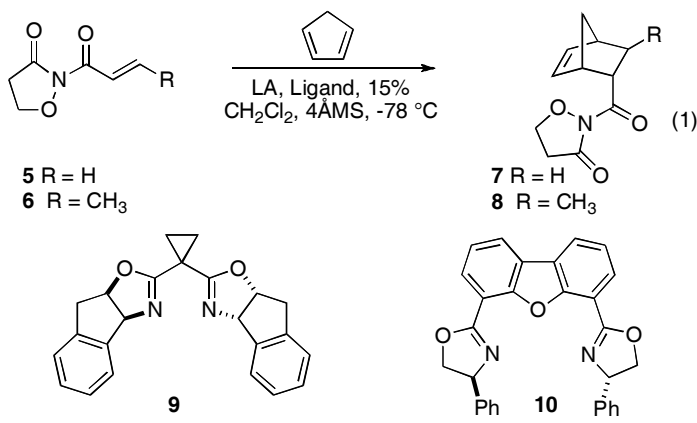

\begin{tabular}{cccccccc}
\hline entry & LA & Lig & $\mathrm{R}$ & $\begin{array}{c}\text { temp } \\
\left({ }^{\circ} \mathrm{C}\right)\end{array}$ & $\begin{array}{c}\text { yield } \\
(\%)^{a}\end{array}$ & $\begin{array}{c}\text { endo: } \\
\text { exo }^{b}\end{array}$ & $\begin{array}{c}\text { ee, \% } \\
(\text { endo })^{c}\end{array}$ \\
\hline 1 & $\mathrm{Cu}(\mathrm{OTf})_{2}$ & $\mathbf{9}$ & $\mathrm{H}$ & -78 & 78 & $99: 1$ & 99 \\
2 & $\mathrm{Mg}\left(\mathrm{NTf}_{2}\right)_{2}$ & $\mathbf{9}$ & $\mathrm{H}$ & -78 & 75 & $99: 1$ & 75 \\
3 & $\left.\mathrm{Ni}_{(\mathrm{ClO}}\right)_{2}$ & $\mathbf{1 0}$ & $\mathrm{H}$ & -78 & 74 & $98: 2$ & 98 \\
4 & $\mathrm{Cu}\left(\mathrm{OTf}_{2}\right.$ & $\mathbf{9}$ & $\mathrm{CH}_{3}$ & 0 & 79 & $93: 7$ & 88 \\
5 & $\mathrm{Mg}\left(\mathrm{NTf}_{2}\right)_{2}$ & $\mathbf{9}$ & $\mathrm{CH}_{3}$ & 0 & 84 & $87: 13$ & 62 \\
6 & $\left.\mathrm{Ni}_{(\mathrm{ClO}}\right)_{2}$ & $\mathbf{1 0}$ & $\mathrm{CH}_{3}$ & $\mathrm{rt}$ & 84 & $92: 8$ & 78 \\
\hline
\end{tabular}

$\overline{{ }^{a} \text { Isolated yields. }{ }^{b} \text { Determined by }{ }^{1} \mathrm{H} \text { NMR. }{ }^{c} \text { Determined by chiral HPLC. }}$ 
Table 2. Cycloadditions with $\alpha$-methylacrylate 3<smiles>C=C(C)C(=O)N1OCCC1=O</smiles>

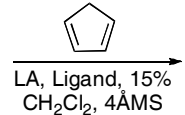
$\mathrm{CH}_{2} \mathrm{Cl}_{2}, 4 \mathrm{MMS}$



11

\begin{tabular}{ccccccc}
\hline entry & \multicolumn{1}{c}{ LA } & Lig & $\begin{array}{c}\text { temp } \\
\left({ }^{\circ} \mathrm{C}\right)\end{array}$ & $\begin{array}{c}\text { yield } \\
(\%)^{a}\end{array}$ & endo:exo $^{b}$ & $\begin{array}{c}\text { ee, } \% \\
\left(\text { endo:exo }^{c}\right.\end{array}$ \\
\hline 1 & $\mathrm{Mg}\left(\mathrm{NTf}_{2}\right)_{2}$ & $\mathbf{9}$ & $\mathrm{rt}$ & 35 & $44: 56$ & $00: 00$ \\
2 & $\mathrm{Zn}\left(\mathrm{NTf}_{2}\right)_{2}$ & $\mathbf{9}$ & $\mathrm{rt}$ & 41 & $52: 48$ & $11: 02$ \\
3 & $\mathrm{Fe}\left(\mathrm{NTf}_{2}\right)_{2}$ & $\mathbf{9}$ & $\mathrm{rt}$ & 95 & $46: 54$ & $45: 31$ \\
4 & $\mathrm{Cu}(\mathrm{OTf})_{2}$ & $\mathbf{9}$ & $\mathrm{rt}$ & 60 & $48: 52$ & $-49:-32$ \\
5 & $\mathrm{Cu}(\mathrm{OTf})_{2}$ & $\mathbf{9}$ & 0 & 52 & $54: 46$ & $-80:-38$ \\
6 & $\mathrm{Cu}(\mathrm{OTf})_{2}$ & $\mathbf{9}$ & -20 & 19 & $63: 37$ & $-87:-43$ \\
$7^{d}$ & $\mathrm{Cu}(\mathrm{OTf})_{2}$ & $\mathbf{9}$ & -20 & 38 & $62: 38$ & $-89:-47$ \\
8 & $\mathrm{Co}\left(\mathrm{ClO}_{4}\right)_{2}$ & $\mathbf{1 0}$ & $\mathrm{rt}$ & 71 & $64: 36$ & $27: 13$ \\
9 & $\mathrm{Co}\left(\mathrm{NTf}_{2}\right)_{2}$ & $\mathbf{1 0}$ & $\mathrm{rt}$ & 92 & $64: 36$ & $42: 30$ \\
10 & $\mathrm{Zn}\left(\mathrm{NTf}_{2}\right)_{2}$ & $\mathbf{1 0}$ & $\mathrm{rt}$ & 97 & $60: 40$ & $65: 42$ \\
11 & $\mathrm{Zn}\left(\mathrm{NTf}_{2}\right)_{2}$ & $\mathbf{1 0}$ & 0 & 72 & $63: 37$ & $71: 48$ \\
12 & $\mathrm{Ni}\left(\mathrm{ClO}_{4}\right)_{2}$ & $\mathbf{1 0}$ & $\mathrm{rt}$ & 64 & $70: 30$ & $92: 62$ \\
13 & $\mathrm{Ni}_{\left(\mathrm{ClO}_{4}\right)_{2}}$ & $\mathbf{1 0}$ & -20 & 21 & $78: 22$ & $95: 75$ \\
$14^{d}$ & $\mathrm{Ni}\left(\mathrm{ClO}_{4}\right)_{2}$ & $\mathbf{1 0}$ & -20 & 29 & $81: 19$ & $96: 80$ \\
\hline
\end{tabular}

${ }^{a}$ Isolated yields. ${ }^{b}$ Determined by ${ }^{1} \mathrm{H}$ NMR. ${ }^{c}$ Determined by chiral HPLC. $d_{30 \mathrm{~mol} \%} \%$ of the catalyst was employed.

yield but the selectivities remained the same (entry 7). We then examined cycloadditions using $\mathbf{1 0}$ as a ligand. A combination of cobalt perchlorate/10 gave the cycloadducts in good yield and modest selectivity (entry 8). Cobalt triflimide was more effective as Lewis acid and gave the cycloadducts in higher yield but with only a small improvement in selectivity (entry 9). Zinc triflimide was also effective and gave reasonable levels of enantioselectivity for the adducts (entries 10 and 11). Of the different Lewis acids examined, nickel perchlorate gave the highest level of selectivity for the cycloadducts (entries 12 to 14). Lowering the reaction temperature led to a small increase in selectivity along with a significant lowering of chemical yield (compare entry 12 with 13 or 14). These experiments demonstrate that it is possible to obtain high level of selectivity for the cycloadduct with a challenging substrate using the new achiral template, 3-isoxazolidinone.

We have carried out a very qualitative study on relative effectiveness of the new achiral template as compared to the traditional ones in the literature by conducting head to head competition experiments. In this study 3 (1 mmol) and another methacrylate appended with a different achiral template $(1 \mathrm{mmol})$ were reacted with excess cyclopentadiene in the presence of magnesium triflimide (2 mmol) (eqn 3). Ligand 9 was added to obtain a homogeneous solution. The reaction was stopped after 3 had undergone $\sim 50 \%$ conversion ( $\sim 6$ hours). The products were isolated after normal work up and yields determined. Results from these experiments are presented in Table 3. Competition between $\mathbf{3}$ and the isomeric oxazolidinone 12 showed that the isoxazolidinone was nearly twice more effective with respect to reactivity. Similarly, substrate $\mathbf{3}$ was $\sim$ five times more reactive than methacrylate appended with a pyrrolidinones template 13 . The pyrazolidinone template $\mathbf{1 4}^{10}$
Table 3. Competition experiments between isoxazolidinone and other templates

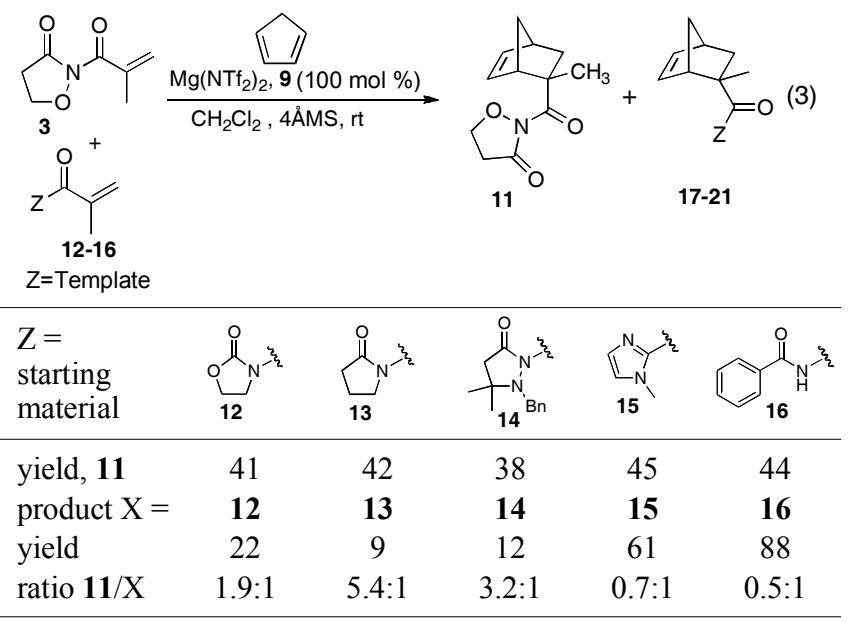

that has proven to be outstanding with respect to selectivity as well as able to provide rotamer control with $\alpha$-substituted acrylates was nearly three times less reactive than the substrate attached to an isoxazolidinone template. Recently Evans and co-workers have introduced 2-acyl imidazoles ${ }^{11}$ as an effective template in enantioselective transformations. A competition experiment between 3 and substrate 15 shows that the acylimidazole derivative is more reactive. In compound $\mathbf{1 5}$, the carbonyl group is in the ketone oxidation state whereas it is in less reactive carboxylic acid oxidation state in $\mathbf{3}$. We have previously shown that imides of type $\mathbf{1 6}$ are quite reactive and have handles to provide rotamer control. ${ }^{12}$ Competition between 3 and $\mathbf{1 6}$ shows that the imide $\mathbf{1 6}$ is twice as reactive than $\mathbf{3}$.

Acknowledgments. We thank the NSF (NSF-CHE-0709061) for financial support of this work.

\section{References}

1. Sibi, M. P.; Chen, J.; Stanley, L. M. Synlett 2007, 298.

2. Matsunaga, S.; Kinoshita, T.; Okada, S.; Harada, S.; Shibasaki, M. J. Am. Chem. Soc. 2004, 126, 7559.

3. Sibi, M. P.; Sausker, J. B. J. Am. Chem. Soc. 2002, 124, 984.

4. Sibi, M. P.; Coulomb, J.; Stanley, L. M. Angew. Chem. Int. Ed. 2008, 47, 9913.

5. For reviews on enantioselective Diels-Alder reactions, see: (a) Reymond, S.; Cossy, J. Chem. Rev. 2008, 108, 5359. (b) Corey, E. J. Angew. Chem. Int. Ed. 2002, 41, 1650. (c) Dias, L. C. J. Brazilian Chem. Soc. 1997, 8, 289.

6. Wolfe, S.; Wilson, M-C.; Cheng, M-H.; Shustov, G. V.; Akuche, C. I. Can. J. Chem. 2003, 81, 937.

7. Desimoni, G.; Faita, G.; Jørgensen, K. A. Chem. Rev. 2006, 106, 3561.

8. Kanemasa, S.; Oderaotoshi, Y.; Wada, E. J. Am. Chem. Soc. 1999, 121,8675 .

9. For selected examples of Diels-Alder reactions with $\alpha$-methylacrylates see: (a) Bondar, G. V.; Aldea, R.; Levy, C. J.; Jaquith, J. B.; Collins, S. Organometallics 2000, 19, 947. (b) Manickam, G.; Sundararajan, G. Tetrahedron: Asymmetry 1999, 10, 2913.

10. Sibi, M. P.; Stanley, L. M.; Nie, X.; Venkatraman, L.; Liu, M.; Jasperse, C. P. J. Am. Chem. Soc. 2007, 129, 395.

11. Evans, D. A.; Fandrick, K. R.; Song, H-J.; Scheidt, K. A.; Xu, R. J. Am. Chem. Soc. 2007, 129, 10029.

12. Sibi, M. P.; Prabagaran, N.; Ghorpade, S. G.; Jasperse, C. P. J. Am. Chem. Soc. 2003, 125, 11796. 